\title{
PLASMA VISCOSITY AND C-REACTIVE PROTEIN AFTER TOTAL HIP AND KNEE ARTHROPLASTY
}

\author{
R. R. CHOUDHRY, R. P. O. RICE, P. D. TRIFFITT, W. M. HARPER, P. J. GREGG
}

From Glenfield General Hospital, Leicester

\begin{abstract}
We studied the changes in plasma viscosity and $\mathrm{C}$-reactive protein to establish normal values after total hip or knee arthroplasty.

Viscosity decreased from $1.68( \pm 0.017)$ to $1.57( \pm 0.014)$ on the first postoperative day and thereafter rose to $1.60( \pm 0.019), 1.75( \pm 0.015)$, and $1.74( \pm 0.011)$ on the third, seventh and fourteenth days respectively. Six to eight weeks after operation it had returned to pre-operative levels. A viscosity above the upper limit of the laboratory range, obtained more than two months after operation, may be considered as abnormal.

The C-reactive protein level increased significantly on the first postoperative day and then decreased from a peak on the second day, attaining nearly normal levels at six to eight weeks after operation. It may be a more sensitive indicator of deep postoperative infection than plasma viscosity.
\end{abstract}

Measurement of the erythrocyte sedimentation rate (ESR) is used in the diagnosis of deep infection after hip or knee arthroplasty (Carlsson 1978; Forster and Crawford 1982), but the time course of its return to normal levels after these procedures is long, three to six months or more (Carlsson 1978; Forster and Crawford 1982; Aalto et al 1984; Shih, Wu and Yang 1987). Estimation of plasma viscosity (PV) is now being used increasingly instead of the ESR but changes in viscosity in the postoperative period have been studied only in a small series during the first six days (Kaperonis et al 1988) making interpretation of later measurements difficult. Creactive protein (CRP) levels are also raised in established deep infection and have been shown to return to normal within two to three weeks of primary surgery (Aalto et al 1984; Shih et al 1987).

We have investigated the time course of changes in PV and CRP levels pre- and postoperatively in patients

R. R. Choudhry, MCh Orth, Orthopaedic Registrar

P. D. Triffitt, MD, FRCS, Senior Orthopaedic Registrar

W. M. Harper, FRCS Ed, Senior Orthopaedic Registrar

Leicester Royal Infirmary, Infirmary Square, Leicester LE1 5WW, England.

R. P. O. Rice, FRCS, Registrar in General Surgery

Nottingham City Hospital, Hucknall Road, Nottingham NG5 1PB, England.

P. J. Gregg, MD, FRCS, Professor of Orthopaedic Surgery

Glenfield General Hospital, Groby Road, Leicester LE39QP, England.

Correspondence should be sent to Mr R. R. Choudhry.

(C) 1992 British Editorial Society of Bone and Joint Surgery

$0301-620 \mathrm{X} / 92 / 4343 \$ 2.00$

J Bone Joint Surg [Br] 1992; 74-B : 523-4.
Table I. Details of the 117 patients under study

\begin{tabular}{lc}
\hline Mean age in years (range) & 66 (25 to 83) \\
Male :female & $43: 74$ \\
& $42: 75$ \\
Knee : hip arthroplasties & \\
& \\
Indications for arthroplasty (per cent) & 80 \\
osteoarthritis & 7 \\
rheumatoid arthritis & 7 \\
aseptic loosening & 3 \\
avascular necrosis & 3 \\
miscellaneous & \\
\hline
\end{tabular}

undergoing total hip or knee arthroplasty to determine normal values.

\section{PATIENTS AND METHODS}

Informed consent was obtained from 117 patients undergoing total hip or knee arthroplasty. The hip replacements were cemented Charnley (DePuy Thackray) or uncemented ceramic arthroplasties, while the knee replacements were cemented or uncemented PFC arthroplasties (PFC modular total knee system, Johnson \& Johnson), randomised as part of another study. After surgery any local or systemic complications were recorded. Details of the patients are shown in Table I.

Blood was obtained before surgery and on postoperative days one, three and seven. Further samples were taken between days ten and 14 depending on the time of discharge and in 30 patients at follow-up six to eight weeks later. Both the PV and CRP levels were estimated.

We compared measurements on different days using 
Student's paired $t$-test, and between different subsets of the patients by the unpaired $t$-test. Values for the CRP in the normal range of $<1 \mathrm{mg} \%$ were considered equal to $1 \mathrm{mg} \%$ for the purpose of analysis.

\section{RESULTS}

The changes in the PV and CRP are shown in Figures 1 and 2. The PV fell from 1.68 to 1.57 on the first postoperative day $(p<0.001)$ and had not fully recovered by the third $(p<0.02)$. Thereafter, it was increased on days seven and $14(p<0.001$ and $p<0.002)$, but to levels only slightly above the upper limit of normal. At six or eight weeks the levels were not significantly different from those before operation.

On the first day the CRP increased significantly above pre-operative levels $(\mathrm{p}<0.001)$, reaching a peak on day two. By the time of discharge the levels were

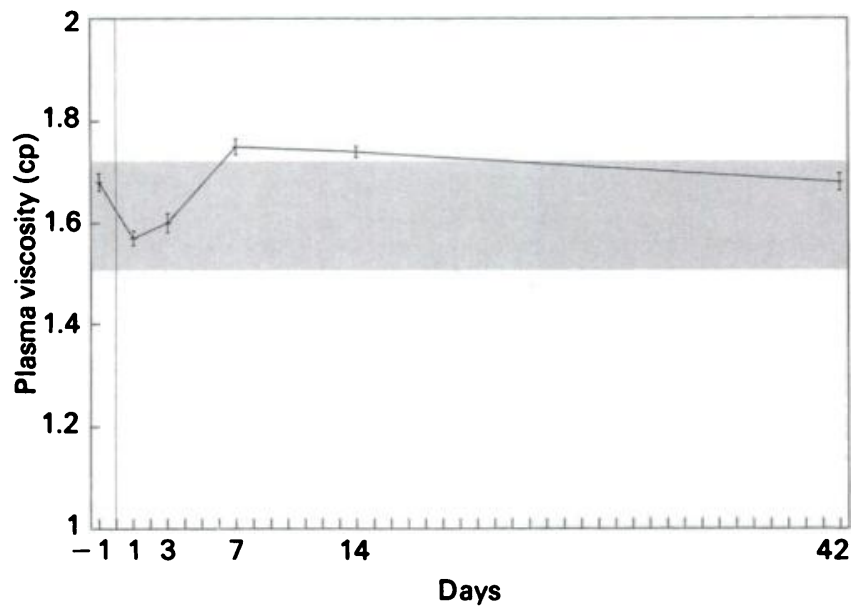

Fig. 1

Plasma viscosity after total hip or knee arthroplasty expressed as mean ( \pm standard error). The shaded area represents the normal range.

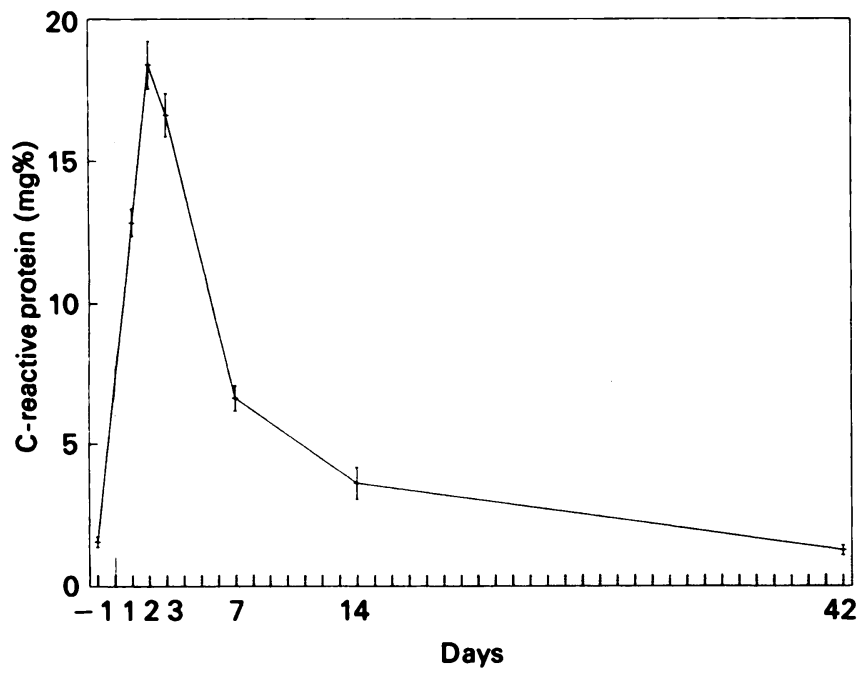

Fig. 2

C-reactive protein after total hip or knee arthroplasty expressed as mean ( \pm standard error). The shaded area represents the normal range. almost normal, but still raised ( $p<0.001$ ). At six or eight weeks after operation, they were not significantly different from those before operation. These findings are in agreement with previous studies.

Pre-operative levels of PV and CRP were above the usual upper limit of normal in 25 and 17 of the patients respectively, with a trend for this to be associated with an indication for surgery other than simple osteoarthritis ( $p<0.07$ and $p<0.06$ respectively, Fisher's exact test). The postoperative changes in these patients showed patterns similar to those of the group as a whole.

The levels of PV and CRP were not related to age, sex, previous history of major surgery, smoking, which joint was replaced, indication for surgery, or the use of cement. The PV on days one and three was significantly lower in those who had a postoperative complication other than venous thrombosis $(p<0.04)$ while in 37 patients who had undergone venography on day six as part of a separate investigation, the CRP was found to be significantly raised between days one and 14 in those with deep-vein thrombosis $(0.003<\mathrm{p}<0.03)$.

\section{DISCUSSION}

We found that the plasma viscosity varied significantly after total hip or knee arthroplasty. The decrease on the first postoperative day has been attributed to a fall in the level of plasma fibrinogen and globulins (Kaperonis et al 1988). The subsequent rise was within a narrow range above the upper limit of normal (1.72 in this laboratory), with a return to normal values much sooner than the ESR. The findings suggest that a PV above the normal range obtained more than two months after operation may be abnormal, assuming that the level was not raised before operation. In clinical practice, however, the greater proportional changes observed in the CRP levels may give a more precise indication of postoperative deep infection (Shih et al 1987).

We thank Messrs I. H. Thomas and T. F. Stoyle for permission to study their patients. We are grateful for the assistance of Dr V. E. Mitchell, Consultant Haematologist, and his staff at Glenfield General Hospital, and the staff of the immunopathology laboratory, Leicester Royal Infirmary.

No benefits in any form have been received or will be received from a commercial party related directly or indirectly to the subject of this article.

\section{REFERENCES}

Aalto K, Österman K, Peltola H, Räsänen J. Changes in erythrocyte sedimentation rate and C-reactive protein after total hip arthroplasty. Clin Orthop 1984; $184: 118-20$.

Carkson AS. Erythrocyte sedimentation rate in infected and noninfected total hip arthroplasties. Acta Orthop Scand 1978; 49: 287-90.

Forster IW, Crawford R. Sedimentation rate in infected and uninfected total hip arthroplasty. Clin Orthop 1982; 168:48-52.

Kaperonis AA, Michelsen CB, Askanazi J, Kinney JM, Chien S. Effects of total hip replacement and bed rest on blood rheology and red cell metabolism. J Trauma 1988; $28: 453-7$.

Shih L-Y, Wu J-J, Yang D-J. Erythrocyte sedimentation rate and Creactive protein values in patients with total hip arthroplasty. Clin Orthop 1987; $225: 238-46$. 